\title{
Novel Micro ElectroMechanical Systems (MEMS) Packaging for the Skin of the Satellite
}

\author{
M. Ann Darrin, Robert Osiander, John Lehtonen, Dawnielle Farrar \\ The Johns Hopkins University Applied Physics Laboratory \\ Laurel, MD 20723 \\ 443-778-4952 / 240-228-4952 \\ ann.darrin@jhuapl.edu; robert.osiander@jhuapl.edu; \\ john.lehtonen@jhuapl.edu; dawnielle.farrar@jhuapl.edu \\ Donya Douglas, Ted Swanson \\ NASA Goddard Space Flight Center \\ Greenbelt, MD 20771 \\ 301-286-6952 \\ donya.m.douglas@gsfc.nasa.gov
}

\begin{abstract}
This paper includes a discussion of the novel packaging techniques that are needed to place MEMS based thermal control devices on the skin of various satellites, eliminating the concern associated with potential particulates from integration and test or the launch environment. Protection of this MEMS based thermal device is achieved using a novel polymer that is both IR transmissive and electrically conductive. This polymer was originally developed and qualified for space flight application by NASA at the Langley Research Center. The polymer material, commercially known as CP1, is coated with a thin layer of ITO and sandwiched between two window-like frames. The packaging of the MEMS based radiator assembly offers the benefits of micro-scale devices in a chip on board fashion, with the level of protection generally found in packaged parts.
\end{abstract}

\section{TABLE OF CoNTENTS}

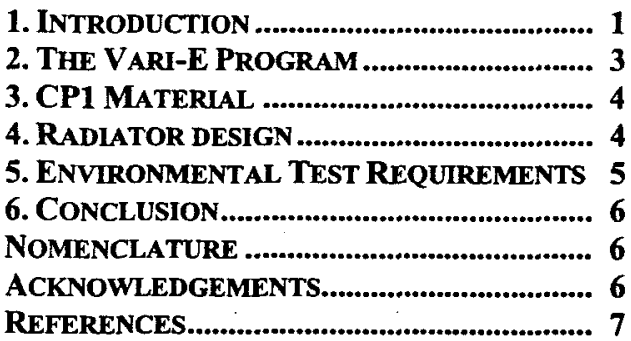

\section{INTRODUCTION}

NASA's New Millennium Program (NMP) endeavors to test new spacecraft technologies for future space missions whose primary objective will be to make multiple simultaneous measurements of the harsh space environment near the boundary of Earth's protective magnetic field known as the magnetosphere. Current satellites weigh hundreds to thousands of grams and use hundreds of watts of heater power. Future missions could involve constellations of $20+$ miniature satellites weighing 5 to 10 $\mathrm{kg}$ each, using a fraction of the power associated with larger spacecraft. The goal of NMP is to validate new technologies that will enable the reduction of weight, size, and cost for future missions. Thermal management of these smaller satellites is currently under development through the Vari-E program [1]. This paper discusses the novel manner in which these smaller satellites could provide an alternate means of thermal control, utilizing a novel packaging technique for the MEMS based technology.

\section{ST-5 Mission}

Space Technology 5 (ST-5), the fourth deep space mission in the NMP, will validate four "enabling" technologies, which are listed in Table 1. Each of the technologies were selected by NMP and fall into two categories, spacecraft miniaturization and constellation technologies. In addition to the four official technologies, ST-5 will fly a miniature digital sun sensor and science grade magnetometer. All of these components will be packaged into a spacecraft weighing $25 \mathrm{~kg}$ or less. ST-5, which is scheduled to launch in May 2005, will fly as a secondary payload on a single expendable launch vehicle (Table 2). The three satellites will be deployed successively into a highly elliptical orbit with a final perigee altitude of at least $200 \mathrm{~km}$ and an apogee altitude of no higher than $38,000 \mathrm{~km}$. Given the goal of NMP, ST-5's main objectives are to: 
(1) Demonstrate the ability to achieve accurate research quality scientific measurements using smaller spacecraft

(2) Design, develop, and operate multiple spacecraft to act as a single constellation rather than as individual elements
(3) Design, develop, integrate, test and operate a fullservice $20-\mathrm{kg}$ class spacecraft through the use of multiple new technologies

Table 1. NMP Technologies.

\begin{tabular}{llc}
\hline Technology & \multicolumn{1}{c}{ Type } & Provider \\
\hline Variable Emittance Thermal Suite & Spacecraft Miniaturization & GSFC \\
Micro-thrusters & Spacecraft Miniaturization & Marotta Scientific Controls \\
Ultra Low Power (1/4 V Logic) & Spacecraft Miniaturization & GSFC \\
Miniature Communications & & \\
Components & Spacecraft Miniaturization & AeroAstro \\
\hline
\end{tabular}

Table 2. Mission Characteristics.

\begin{tabular}{|c|c|}
\hline Number of Satellites & 3 \\
\hline $\begin{array}{l}\text { Mission Orbit } \\
\text { Perigee } \\
\text { Apogee } \\
\text { Inclination } \\
\text { Period } \\
\text { Eclipse Duration }\end{array}$ & $\begin{array}{l}240 \mathrm{~km} \text { (minimum) } \\
37,000 \mathrm{~km} \text { (maximum) } \\
15 \text { to } 28.5^{\circ} \\
10.5 \mathrm{hrs} \\
1 \text { hour (maximum) }\end{array}$ \\
\hline Mission Lifetime & 3 months minimum, 6 months goal \\
\hline Spin Rate & 20 rpm (fully deployed) \\
\hline Launch System & Secondary Payload on EELV \\
\hline Orbit Adjust & Cold Gas System \\
\hline Mass & $<25 \mathrm{~kg}$ \\
\hline Size & $50.8 \mathrm{~cm}$ Diameter $\times 28.3 \mathrm{~cm}$ High \\
\hline Power (Available to load) & $\sim 18.823$ watts EOL \\
\hline Data & Max of $100 \mathrm{kbps}$ \\
\hline $\begin{array}{l}\text { Attitude Control } \\
\text { Control: } \\
\text { Knowledge: }\end{array}$ & $\begin{array}{l}\text { Spin Stabilized, with spin axis perpendicular to the sun } \\
\pm 5^{\circ} \text { (spin axis pointing control, } 3 \sigma \text { ) } \\
\pm 1^{\circ} \text { (spin axis pointing knowledge, } 3 \sigma \text { ) }\end{array}$ \\
\hline $\begin{array}{c}\text { Communications } \\
\text { Routine } \\
\text { Command }\end{array}$ & $\begin{array}{l}\text { X-Band } \\
\text { X-Band }\end{array}$ \\
\hline $\begin{array}{l}\text { Telemetry } \\
\text { Clock Accuracy: }\end{array}$ & Knowledge to $5 \mathrm{msec}$ \\
\hline
\end{tabular}




\section{The VARI-E Program}

Variable Emittance (Vari-E) coatings have proved applicable to a wide range of space applications, particularly in the area of radiators [3]. Studies reveal that Vari-E coatings offer substantial savings in mass and/or power over traditional approaches (i.e., large heaters, variable conductance heat pipes, and mechanical louvers) [1]. There are two (2) different technologies associated with the ST-5 mission. The two technologies are electrophoretic and Micro ElectroMechanical Systems (MEMS). This paper discusses the use of a Vari-E infrared radiator coating with MEMS shutters that can be opened or closed to vary the emissivity of the radiator surface, thereby providing a thermal path from the external environment to the spacecraft. Utilization of these characteristics on small spacecraft allows us to maintain the same benefits associated with traditional techniques, but on a much smaller scale. Success in this area could lead to great advancements in emerging technologies that require small, low power, and more cost efficient instruments.

The Johns Hopkins University Applied Physics Laboratory (APL) MEMS Variable Emittance Coating (VEC) Instrument consists of two components, namely, the MEMS Shutter Array (MSA) radiator and the Electronic Control Unit (ECU). The MSA radiator is physically located on the top deck of the spin-stabilized ST-5 spacecraft whereas the ECU will be located within the spacecraft. The MSA radiator can be operated in both manual and autonomous mode, to evaluate both high and low emittance states.

The MSA radiator is a variable emittance device, consisting of two sections, each containing 18 MEMS Shutter Die (MSD). The sections are divided into three subsections each (6 MSD/subsection), which are independently controlled by the ECU. The shutters are in a closed position when no power is supplied, and open upon the application of a 60 -volt DC signal. The shutters can be independently controlled by the ECU. In manual mode, all shutters can be commanded to be either all open or all closed. In automatic mode, the ECU has the ability to independently control the shutter position of the different sections of the MSA and determine the resulting change in radiator substrate temperature. The temperature results are significant because they provide a quantitative record of how well the instrument performs as a thermal device (i.e., functional radiator). The ECU transmits the readings of four temperature sensors, the shutter arrangement, and the shutter status to C\&DH in both automatic and manual mode.

A block diagram depicting the major functional components of the ECU is illustrated in Figure 1.

The overall operation is a follows: The Electrical Power System (EPS) supplies $5.23 \pm 0.1$ volts to the ECU. The 5.23 volts powers the ICs and is then stepped up to 60 volts to properly power the MEMS comb drives as illustrated in Figure 1. Once powered, the MEMS instrument can now be properly controlled. At such time, the microcomputer sends its status information out to $\mathrm{C} \& D H$, and awaits command. $\mathrm{C} \& \mathrm{DH}$ sends two different bi-level commands to the ECU, which are examined and executed via the ECU. The bilevel commands are Automatic/Manual and Hi-E/Lo-E. These two bi-level commands tell the ECU whether its processing unit will be in full control of the MEMS device, or if $C \& D H$ will command the state of the shutters. Provided C\&DH sends the Automatic command to the ECU, the ECU is in total control of the MEMS device. In Automatic mode, the microcomputer is capable of controlling each section of the

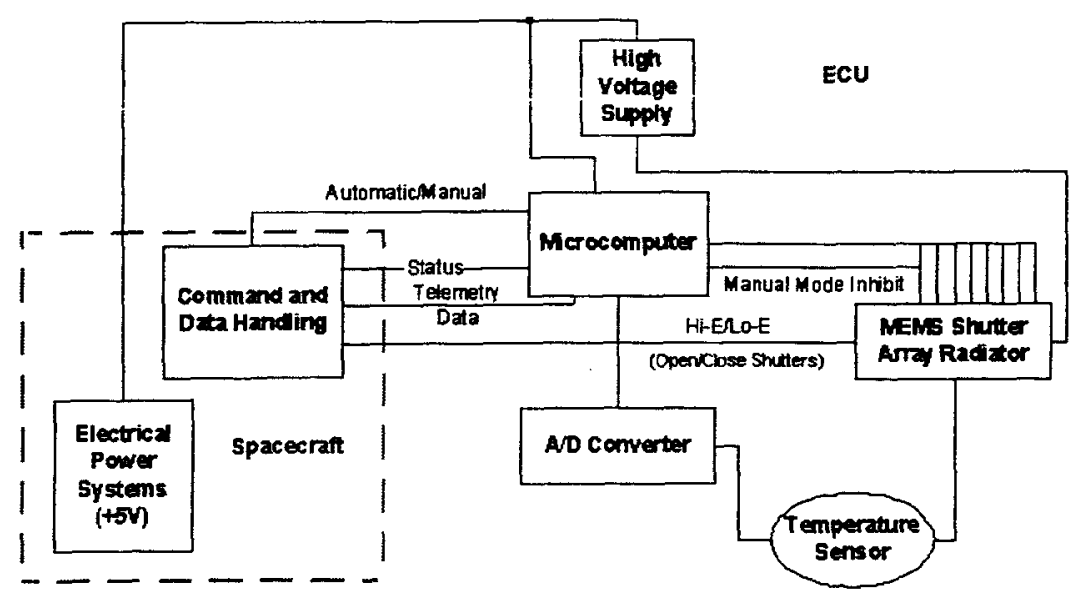

Figure 1. Functional Block Diagram 


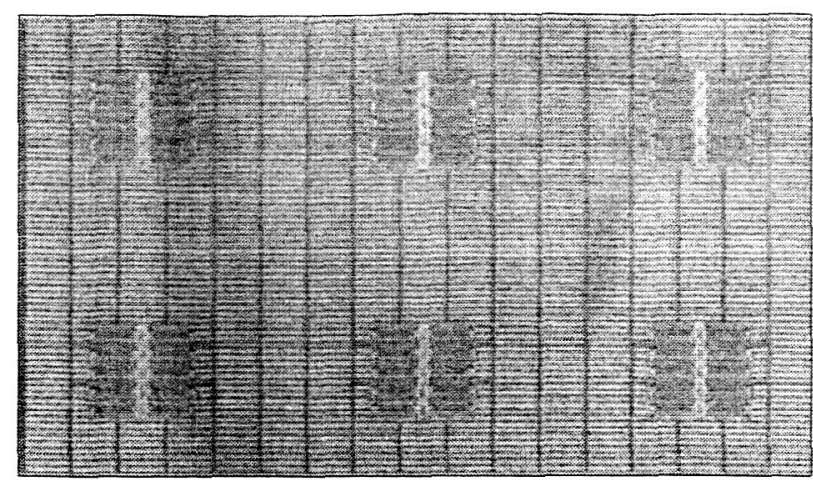

Figure 2. MEMS Shutter Building Block ( $w / 6$ comb drive units).

MEMS device independently. The MSA radiator assembly consists of 36 MEMS Shutter Die (MSD), with 18 MSD per section, as depicted in Figure 3. Each MSD is $12.8 \mathrm{~mm} \times$ $13.1 \mathrm{~mm}$, consisting of 72 MEMS Shutter Building Block (MSBB). The MSBB is the smallest shutter unit, $1.77 \mathrm{~mm}$ $\times .88 \mathrm{~mm}$, driven simultaneously by 6 comb drive units. An enlarged view of a MSBB is provided in Figure 2.

\section{Unique Packaging Drivers of the MSA Radiaior Assembly}

For the ST-5 Program, the MSA radiator is confined to a $9 \mathrm{~cm}(\mathrm{~L}) \times 10 \mathrm{~cm} \mathrm{(W)} \times 3 \mathrm{~cm}(\mathrm{H})$ enclosure. To ensure protection of the MSD when exposed to the environment, a protective cover was investigated. Studies have found that space based optical instruments are susceptible to accumulation due to out-gassing of organic materials. For this reason, designers take great pains to select materials from the NASA approved list. In addition to these kinds of contaminants is random particulate matter (dust) which can accumulate. For the MSA radiator application, this dust can lodge within the hinges of the MEMS shutters and prohibit movement. Placing a protective window over the MSA is the obvious solution, but even the protective window must meet the GSFC material requirements. In this application the external surface of the window must be electrically conductive, and if made of an organic material, must be resistant to attack by elemental oxygen.

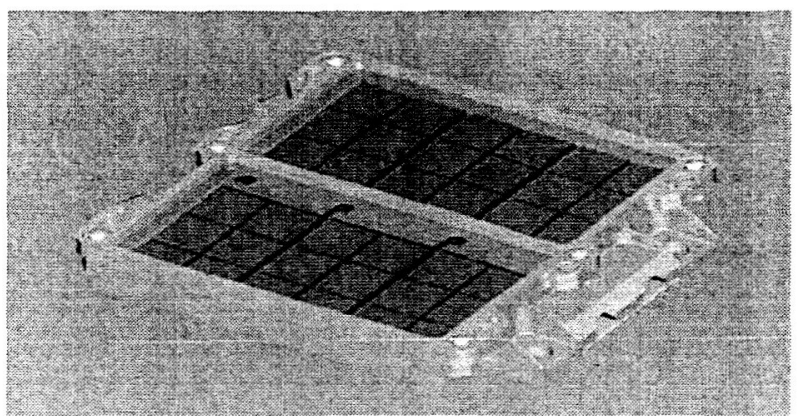

Figure 3. MSA Radiator Assembly

\section{CP1 Material}

LaRC TM-CP1 polyimide is a revolutionary high performance material with a wide variety of uses in space structures, thermal insulation, electrical insulators, industrial tapes and advanced composites. It provides superior physical and electrical properties over a wide temperature range and in a number of harsh environments. This fluorinated polyimide may be dissolved readily in a number of solvents for use in various applications such as castings and coatings. CP1 is superior for long-duration, spacebased applications where transparency is needed for functionality and is rated for a 10 year life in Geosynchronous Earth Orbit (GEO). For applications requiring transparency, $\mathrm{CP} 1$ is colorless and offers better space UV-radiation resistance than most known polymer materials (including other polyimides, polyesters, Teflon, Teflon-based materials, and others). Other polyimides tend to be costly, absorb too much solar energy, have lower UV resistance and are not as transparent as CP1. Materials that do have similar transparency to CP1 degrade more rapidly in the harsh environment of space.

At present, $\mathrm{CP} 1$ is available in powder and film form. The knowledge gained through the research and development of inflatable structures has led to the development of techniques which are being used for the production of these films in rolled form. Through the sponsorship of NASA LaRC, SRS has developed a pilot-scale machine capable of producing $\mathrm{CP} 1$ polyimides in continuous roll form. Rolled films have been manufactured measuring $0.61 \mathrm{~m}(2 \mathrm{ft})$ in width, with thickness ranging from $0.0025 \mathrm{~mm}(0.1 \mathrm{mil})$ to $0.0254 \mathrm{~mm}$ (1.0 mil). Commercial manufacture of CP1 is scaling up to increase production to widths exceeding $1.2 \mathrm{~m}$ $(4 \mathrm{ft})$. For the ST-5 mission, CP1 proved to be the material of choice to serve as a protective film for the MSA radiator assembly. Table 3 lists the properties of this material.

\section{RADIATOR DESIGN}

The MSA radiator assembly consists of a chassis, where MSBBs are attached to the top of the chassis via an ALN carrier. Each MSBB is activated by one of 22 discrete control wires from the ECU. Bonded and fastened to the underside is a printed wiring board (PWB) to assist in communication between the ECU and MSA radiator assembly. The control wires gather along the center rib of the PWB assisting in the signal path from the hamess to the MEMS shutters. For ground testing, a Ground Support Equipment (GSE) cover protects the MSA radiator assembly prior to launch. Throughout the life of the mission, an IR transmissive window assembly protects the MSD from the impact of random particulate matter in space. In the Vari-E experiment for ST-5, the MSA radiator is thermally isolated from the spacecraft, as the Vari-E technologies on this mission are for validation and as such are not mission critical. The thermal results associated with opening and 
closing the shutters is measured by thermistors that are located on the underside of the MSA radiator chassis. The thermistor data is collected and telemetered to a monitoring ground station An exploded view of the MSA radiator assembly is shown in Figure 4.

Table 3. CP1 Properties.

\begin{tabular}{|c|c|}
\hline Properties & $\mathrm{LaRC}^{\mathrm{TM}} \mathrm{CP1}$ \\
\hline Film Color (\%T@ 900 nm / 1 mil Film) & Pale Yellow to Colorless \\
\hline Film Density & $1.434 \mathrm{~g} / \mathrm{cc}$ \\
\hline Solubility at Room Temperature & DMAC, DMF, NMP, MIBK \\
\hline Glass Transition Temperature & $263^{\circ} \mathrm{C}$ \\
\hline Polymer Decomposition Temperature & $530^{\circ} \mathrm{C}$ \\
\hline Dielectric Constant (@10 GHz) & $2.4-2.5$ \\
\hline Refractive Index & 1.58 \\
\hline Inherent Viscosity of Polyamic Acid @ $35^{\circ} \mathrm{C}$ & $1.2-1.6 \mathrm{dl} / \mathrm{g}$ \\
\hline UV Cut Off (0.2 mil Film) & $320 \mathrm{~nm}$ \\
\hline Imide IR Bands & 1780,1725 , and $745 \mathrm{~cm}^{-1}$ \\
\hline Specific Heat. Cp (@ 25ํ) & $1.094 \mathrm{~J} / \mathrm{g}^{\circ} \mathrm{C}$ \\
\hline Tensile Strength & $14.5 \mathrm{ksi}$ \\
\hline Tensile Modules & $315 \mathrm{ksi}$ \\
\hline CTE & $51.2 \mathrm{ppm} /{ }^{\circ} \mathrm{C}$ \\
\hline Solar Absorptance. Full Spectrum (Uncoated Film) & $0.072(0.25 \mathrm{mil})$ \\
\hline Solar Absorptance. Full Spectrum (Coated Film. Aluminum) & $0.106(0.25 \mathrm{mil})$ \\
\hline IR Emittance. Hemispherical, 300K (Uncoated Film) & $0.194(0.25 \mathrm{mil})$ \\
\hline IR Emittance. Hemispherical, 300K (Coated Film. Aluminum) & 0.03 \\
\hline
\end{tabular}

The MEMS die are fabricated in wafer format, very similar to an integrated circuit. The wafers go through a standard backside grind process and then are released, diced, tested, gold coated, and functionally tested again, in preparation for final attach. The individual die are bonded to aluminum nitride (AIN) carriers that are subsequently bonded to the MSA chassis. This design allows for optimum rework/replacement of each MSD as necessary.

Of most significance is the window assembly. As stated previously, the MEMS based comb drives are sensitive to contamination, which is abundant in space. For this reason the MEMS must be protected by an IR transparent window that is also electrically conductive. The polyimide material, developed by Langley Research Center located in Newport News, Virginia, was selected. A film, less than 4 mils thick, is sandwiched in tension between two window frames and bonded in place, as shown in figure 3 . CP1 in its relaxed state is flaccid and must be stretched to provide the mechanical protection from debris impact. To ensure a taut connection, the CP1 is procured in a taut configuration, and then epoxied to one side of the window and then cured. Sandwiching the CP1 attach between the two windows, reinforces the connection. With the window assembly in place, the CP1 film is suspended several millimeters above the shutters, thus providing a barrier layer between the actual die and the environment.

Electrical conductivity of the film is achieved through application of a thin coating of indium tin oxide. known in the industry as ITO. Although the ITO has a milky opaque appearance, in sufficiently thin coatings it does not change the IR performance of the window. ITO serves to protect the CP1 from degradation in the presence of atomic oxygen. All the structural members of the MSA radiator assembly are made of aluminum 6061 and finished with a clear anodize treatment, followed by a yellow irridite.

\section{ENVIRONMENTAL TEST REQUIREMENTS}

Several environmental tests must be conducted on the final flight design. Table 4 provides a summarized list of the various performance tests that will be conducted to verify 


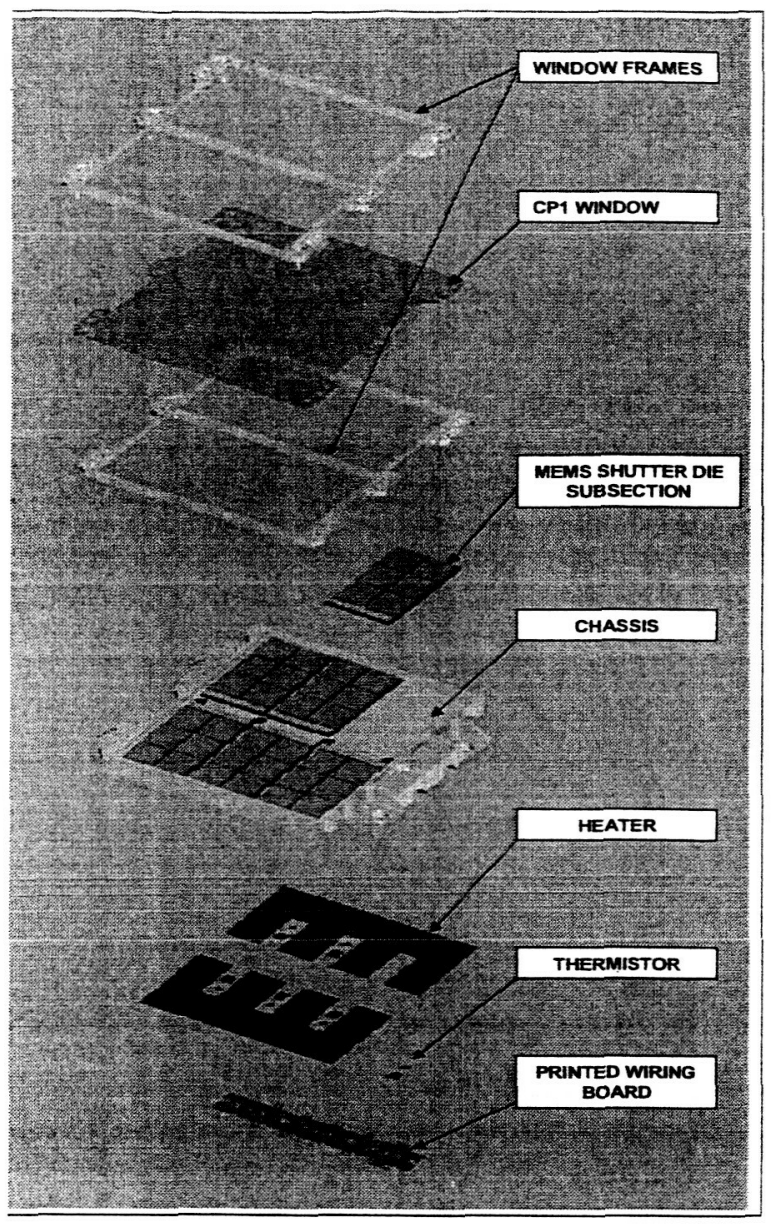

Figure 4. Exploded View of the MSA Radiator Assembly.

survival. In addition to the test listed, life cycling tests, performance measurements (both effective IR emissivity and solar absorptivity), cycling in vacuum (over 1000 times), and exposure to a simulated space environment in GSFC's Solar Wind and UV facilities will be conducted.

\section{Conclusion}

This paper has presented an overview of the ST-5 mission with emphasis on the Variable Emissivity (Vari-E) MEMS technology. The purpose of ST-5 is to evaluate an array of new technologies for future spacecraft and constellation technology missions. In particular, the Vari-E experiment explores the feasibility of using MEMS shutters to control the emissivity of a radiant heat exchanger which would ultimately control the heat loss and absorption for miniature spacecraft. In addition to the innovative MEMS based approach, this paper also discusses unique challenges of the space environment, as well as ways to protect the MEMS shutters from contamination within such a harsh environment. The solution employs a LaRC-developed polyimide film that is IR transmissive, and coated with ITO to aid in protection against atomic oxygen.
Table 4. Required Environmental Tests for the ECU and MSA Radiator Assembly

\begin{tabular}{|c|c|}
\hline Test & Conditions \\
\hline Random Vibration & $\begin{array}{l}\text { Flight (Limit) Level }+3 \mathrm{~dB} \text {, Flight } \\
\text { Duration/axis; } 3 \text { axes }\end{array}$ \\
\hline Sinusoidal Vibration & $\begin{array}{l}1.25 \times \text { Flight (Limit) Level, Flight } \\
\text { Duration/axis; } 3 \text { axes } 4 \text { oct } / \mathrm{min}\end{array}$ \\
\hline Acoustics & $\begin{array}{l}\text { Flight (Limit) Level }+3 \mathrm{~dB} \text {, Flight } \\
\text { Duration }\end{array}$ \\
\hline Structural Loads & $\begin{array}{l}\text { Test: } 1.25 \times \text { Flight }(\text { Limit) Loads, } \\
\text { Analysis: } \\
1.4 \times \text { Flight }(\text { Limit }) \text { Loads }\end{array}$ \\
\hline Mechanical Shock & Analysis: $1.4 \times$ Flight (Limit) Level \\
\hline $\begin{array}{l}\text { Thermal } \\
\text { Cycle/Vacuum }\end{array}$ & $\begin{array}{l}-60 \text { to }+60^{\circ} \mathrm{C}, 4 \text { cycles }(\mathrm{min}), 1 \times 10^{-5} \\
\text { torr }\end{array}$ \\
\hline Burn In & $100 \%\left(125^{\circ} \mathrm{C}, 160\right.$ hours $\left.\min \right)$ \\
\hline
\end{tabular}

\section{NOMENCLATURE}

ST-5 Space Technology - 5

ECU Electronic Control Unit

C\&DH Command and Data Handling

MEMS MicroElectroMechanical Systems

MSA MEMS Shutter Array $(9 \mathrm{~cm} \times 10 \mathrm{~cm} \times 3 \mathrm{~cm}, 36$ MSA on radiator)

MSBB MEMS Shutter Building Block: The smallest shutter unit, $1.77 \mathrm{~mm} \times .88 \mathrm{~mm}$, driven simultaneously by 6 comb drive units

MSD MEMS Shutter Die (12.8 mm $\times 13.1 \mathrm{~mm}, 72$ MSBB)

EPS Electrical Power System

VEC Variable Emittance Coating

\section{ACKNOWLEDGEMENTS}

APL is the principal investigator of the Variable Emittance (MEMS) Electronic Control Unit and the MSA Radiator. The MEMS wafers are fabricated at Sandia National Laboratories. Funding is provided by the NASA GSFC Thermal Control Branch and ST-5 Project Team. APL would also like to acknowledge SRS Technologies for supplying the CP1 polymer that serves as a protective film for the MSA Radiator (http://www.stg.srs.com/atd/ advpolymers.htm). 


\section{REFERENCES}

[1] D. M. Douglas, T. D. Swanson., R. Osiander, J. L. Champion, A. Darrin Garrison, W. Biter, and P.

Chandrasekhar, "Development of the Variable Emittance Thermal Suite for the Space Technology 5 Microsatellite," Proceedings of Space Technology and Applications International Forum (STAIF-2002), edited

by M. El-Genk, AIP Conference Proceedings, New York, 2000.

[2] D. Farrar, W. Schneider, R. Osiander, J. L. Champion, A. G. Darrin, D. Douglas, and T. D Swanson, "Controlling Micro Electro-Mechanical Systems (MEMS) in Space," Proceedings of Space Technology and Applications International Forum (STAIF-2003), edited by M. El-Genk, AIP Conference Proceedings, New York, pp. 180-186, 2003.

[3] Garrison Darrin, A, Osiander, R., Champion, J.L., Swanson, T.D., Douglas, D. Grob, L.M., "Variable Emissivity Through MEMS Technology," in proceedings of Space Technology and Applications International Forum (STAIF-2000), edited by M. El-Genk, AIP Conference Proceedings, New York, 2000, pp. 947-961. 


\section{Ann Garrison Darrin}

Ms. Darrin is the Technology Programs Manager for the

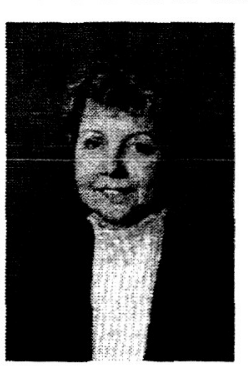

Electronic Services Group at the Johns Hopkins University Applied Physics Laboratory. She has over 20 years experience in both government (NASA, DoD) and private industry in particular with technology development, application, transfer and insertion into space flight missions. She holds an M.S. in Technology Management and has authored several papers on technology insertion along with co-authoring several patents. Ms. Darrin was the Division Chief at NASA Goddard Space Flight Center for Electronic Parts, Packaging and Material Sciences from 1993-1998. She has extensive background in aerospace engineering management, microelectronics and semiconductors, packaging, and advanced miniaturization; is a recognized expert in 3-D packaging, advanced interconnect, and engineering management; and has been instrumental in several applied technology breakthroughs.

\section{Donya M. Douglas}

Ms. Donya M. Douglas is the Thermal Product Design Lead

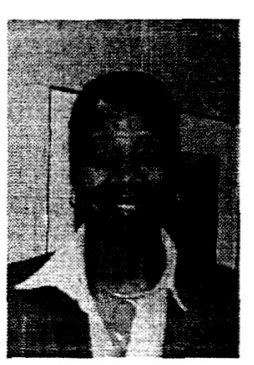
and the Variabie Emittance Coatings Instruments Manager for the Space Technology 5 Project at NASA/ Goddard Space Flight Center in Greenbelt, Maryland. She graduated from University of Maryland at College Park in 1994 with a BS in Mechanical Engineering and has worked at Goddard for more than 10 years. Her areas of expertise include research and development of two-phase thermal control devices for spacecraft such as Capillary Pumped Loops (CPLs) and Loop Heat Pipes (LHPs), state-of-the-art research into variable emittance coatings, and spacecraft and instrument thermal design and control. During her tenure, Ms. Douglas has pubiished and presented more than fifteen technical papers, as author or co-author.

\section{Dawnielle Farrar}

Dawnielle Farrar is an Electrical Engineer at Johns Hopkins

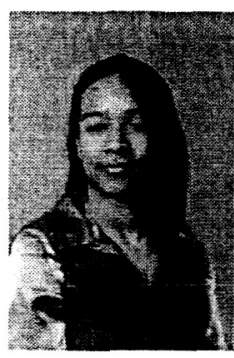
University Applied Physics Laboratory (JHU/APL). She holds a M.S in Electrical Engineering from Johns Hopkins University, and two B.S. degrees in Electrical Engineering and Physics from University of Maryland College Park and Lincoln University, respectively. Ms. Farrar has worked on a variety of programs while employed with the laboratory, ranging from Infra-Red Communication (IRCOMM) to an Interface Electronics Module (IEM) for the mission to Pluto known as New Horizons. Her professional responsibilities have included
IC design, simulation, and the development of hardware and software for both space and commercial applications. Ms. Farrar has published and presented several technical papers as author or co-author, and is currently the design engineer for the electronic control unit that will drive the variable emittance Micro Electro-Mechanical Systems (MEMS) based thermal control radiator for the Space Technology-5 mission through NASA GSFC.

\section{S. John Lehtonen}

John Lehtonen received a B.S. degree in electrical

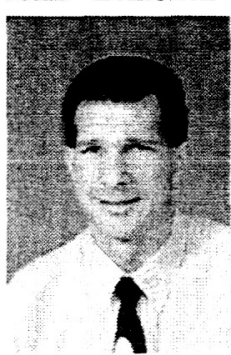
engineering from Florida Atlantic University in 1985 . He is a Senior Staff engineer with the Electronic Services Group at Johns Hopkins University Applied Physics Laboratory where he is involved with advanced microelectronics packaging technology development. Some of his recent projects include hybrid microcircuits for New Horizons, MESSENGER and TIMED spacecrafts. Before joining JHUAPL in 1991, he worked at Solitron Devices, Inc., as a project engineer for the hybrid microcircuits being made for the AMRAAM and HARM missiles programs. His current interests include highreliability assembly process development for multichip modules, chip on board, and flip chip packaging technology development for use in spacecraft instrumentation. Mr. Lehtonen has worked for 18 years in the microelectronics field and is a member of IMAPS (International Microelectronics and Packaging Society).

\section{Robert Osiander}

Dr. Osiander received his $\mathrm{Ph}$. D. in Physics from the

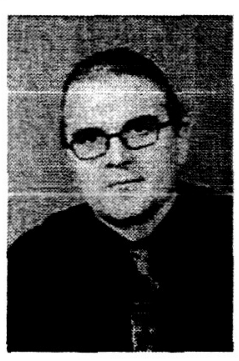
Technical University in Munich, Germany, in 1991. He is presently Assistant Group Supervisor of the Sensor Science Group in the Research \& Technology Development Center at the Johns Hopkins University Applied Physics Laboratory. His current research interests include Micro-ElectroMechanical Systems (MEMS), Nanotechnology, and Terahertz Imaging and Technology for Applications in Sensors, Communications, Thermal Control, and Space. He is the PI on "MEMS Shutters for Spacecraft Thermal Control", which is one of NASA's New Millennium Space Technology Missions, to launch in 2005, and on two other NASA funded programs on a MEMS Plasma Spectrometer and a MEMS Stirling Engine. Further MEMS research interests are in Silicon on Sapphire, in CVD diamond and polymer MEMS devices. Dr. Osiander was the co-recipient of the 2002 APL Invention of the Year Award. His bio includes many US Patents and publications. 
Theordore D. Swanson

Theodore Swanson is currently Assistant Chief for

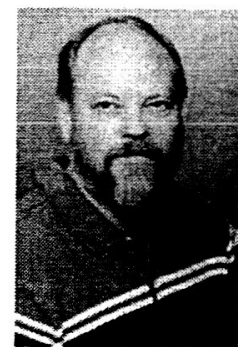

Technology, Mechanical Systems

Division, at NASA's Goddard Space

Flight Center. In this role he has overall

responsibility for the identification and insertion of new thermal, mechanical, and electro-mechanical technologies into operational spacecraft and instruments for the Division. Mr. Swanson has 30 years professional experience with the last 19 at Goddard, first in the Thermal Engineering Branch and most recently at the Division level. Prior to joining NASA in 1984 he was a private consultant, and before that he was with the Johns Hopkins Applied Physics Laboratory. He has a MS from the University of Maryland, a BS from the Case institute of Technology, has authored/co-authored over 50 technical publications, has several patents, and has co-authored two technical books. The Center Director recently appointed Mr. Swanson to be a "Goddard Senior Fellow." 